\title{
Content of a radiology report
}

\author{
Mervyn Cohen
}

Received: 30 June 2009 / Accepted: 8 July 2009 / Published online: 5 August 2009

(C) Springer-Verlag 2009

Sir,

I read with interest the recent publication on clinicians' interpretations of radiology reports in wheezing and nonwheezing febrile children [1]. Like the authors, I am concerned with the varied interpretations that the pediatricians make from our radiology reports. Clearly there is a communication problem.

There is a simple solution. The referring pediatrician should not be the person to draw a conclusion from the description of the findings in the images. This must be done by the radiologist.

Too often the radiology report is an excellent description of the findings in the image, yet the conclusion is poor or absent. I believe that the critical component of the radiology report is not what we see, but what we think. The most important part of our imaging report should be the conclusion $[2,3]$. In a patient presenting with new signs and symptoms (such as a febrile child), the conclusion of the imaging report must contain a differential diagnosis or, when possible, a definitive diagnosis $[2,3]$. All too often the conclusion of the report is merely a restatement of findings.

I suggest that if every imaging report in the study had a definitive conclusion, with diagnosis or differential diagnosis, referring pediatricians would not be made to draw their own diagnostic conclusion from the radiologist's description of the findings. This will have been done by the radiologist.

\section{References}

1. Spottswood SE, Liaw K, Hernanz-Schulman M et al (2009) The clinical impact of the radiology report in wheezing and nonwheezing febrile children: a survey of clinicians. Pediatr Radiol 39:348-353. doi:10.1007/s00247-009-1154-4

2. Lee R, Cohen MD, Jennings GS (2006) A new method of evaluating the quality of radiology reports. Acad Radiol 13:241-248

3. Cohen MD, Curtin S, Lee R (2006) Evaluation of the quality of radiology requisitions for intensive care unit patients. Acad Radiol $13: 236-240$

M. Cohen $(\bowtie)$

Department of Radiology, Indiana University, Riley Hospital,

702 Barnhill Drive, Room 1053,

Indianapolis, IN 46202, USA

e-mail: mecohen@iupui.edu 